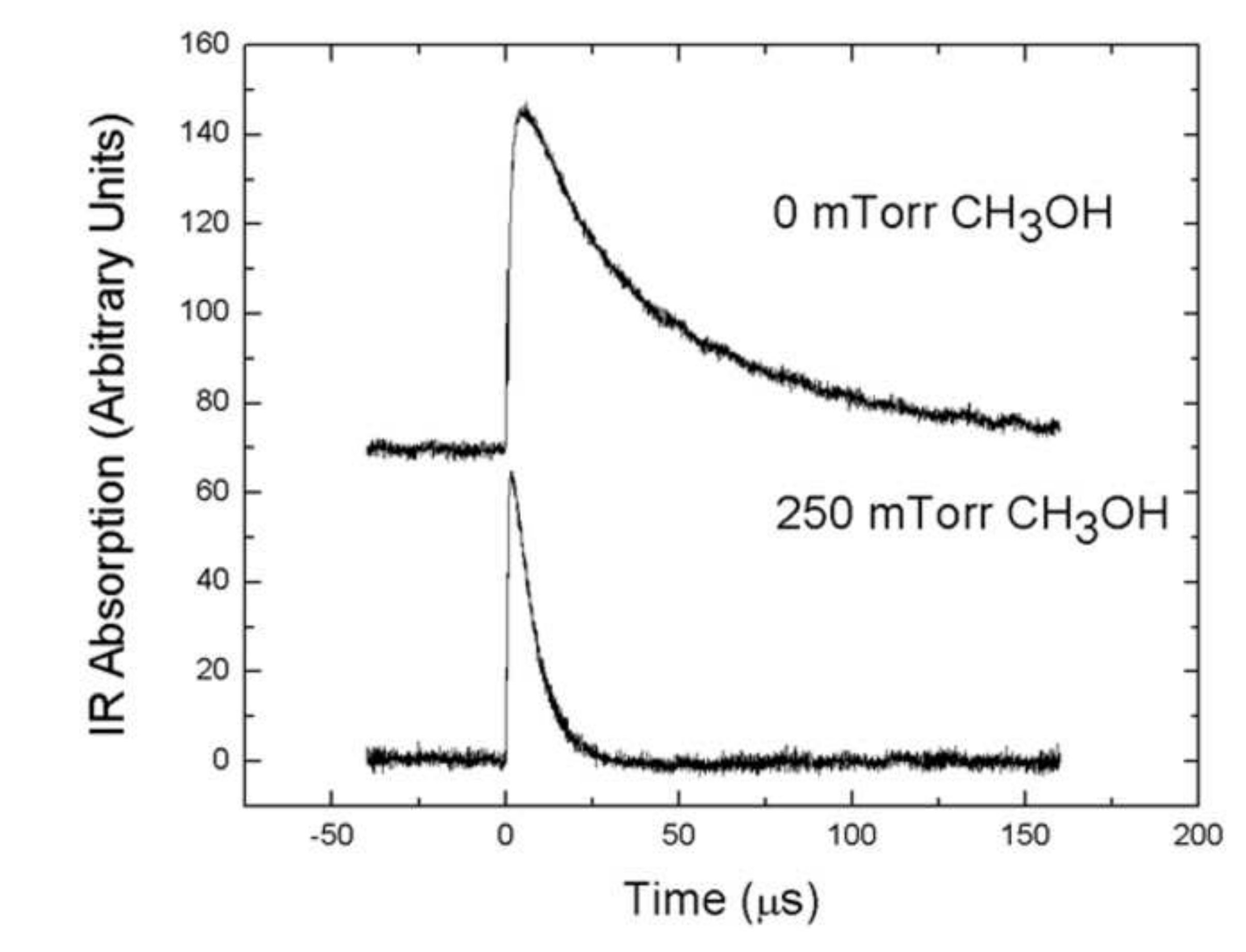




\title{
Reaction Kinetics of the CN Radical with Primary Alcohols
}

\author{
Erik Janssen and John F. Hershberger ${ }^{*}$ \\ Department of Chemistry and Biochemistry, Dept. 2735, PO Box 6050, \\ North Dakota State University, Fargo, ND 58108-6050
}

\begin{abstract}
The kinetics of the reactions of $\mathrm{CN}$ radicals with several small primary alcohol molecules were studied by transient infrared laser absorption spectroscopy. Direct time-resolved detection of $\mathrm{CN}$ was used to determine total rate constants. In addition, $\mathrm{HCN}$ and DCN products were detected in order to estimate the branching ratios of the $\mathrm{CN}+\mathrm{CH}_{3} \mathrm{OH}$ reaction. We find that abstraction of an alkyl hydrogen atom dominates the $\mathrm{CN}+\mathrm{CH}_{3} \mathrm{OH}$ reaction, but a small, $\sim 8 \%$ yield of hydroxyl hydrogen abstraction is also observed.
\end{abstract}

Corresponding author. Email: john.hershberger@ndsu.edu. FAX (701)-231-8831 


\section{Introduction}

The kinetics of the $\mathrm{CN}$ radical are of interest due to the role of this molecule in combustion chemistry, especially in relation to formation and removal of $\mathrm{NO}_{\mathrm{X}}$. CN reactions with a variety of molecules have been previously studied, including both saturated and unsaturated hydrocarbons[1-7], $\mathrm{O}_{2}[1,8-16]$, $\mathrm{NO}[15,17]$, and $\mathrm{NO}_{2}[16,17]$. Past work in our laboratory has included study of $\mathrm{CN}$ reactions with $\mathrm{O}_{2}$ [18,19], $\mathrm{NO}_{2}$ [20], OCS [21], $\mathrm{CS}_{2}$ [22], $\mathrm{SO}_{2}$ [22], and $\mathrm{HCNO}[23,24]$. To date, however, there is no literature on the kinetics of $\mathrm{CN}$ reactions with alcohols.

In this study, we report measurements of total rate constants of the reactions of $\mathrm{CN}$ with several small primary alcohols:

$$
\begin{array}{ll}
\mathrm{CN}+\mathrm{CH}_{3} \mathrm{OH} & \rightarrow \mathrm{HCN}+\mathrm{CH}_{2} \mathrm{OH} \\
& \rightarrow \mathrm{HCN}+\mathrm{CH}_{3} \mathrm{O} \\
\mathrm{CN}+\mathrm{CH}_{3} \mathrm{CH}_{2} \mathrm{OH} & \rightarrow \mathrm{HCN}+\mathrm{CH}_{2} \mathrm{CH}_{2} \mathrm{OH} \\
& \rightarrow \mathrm{HCN}+\mathrm{CH}_{3} \mathrm{CHOH} \\
& \rightarrow \mathrm{HCN}+\mathrm{CH}_{3} \mathrm{CH}_{2} \mathrm{O} \\
\mathrm{CN}+\text { n-propanol } & \rightarrow \text { products }
\end{array}
$$

We also report measurements of $\mathrm{HCN}$ and DCN product yields in reactions of $\mathrm{CN}$ with partially deuterated methanol in order to determine the competition between channel (1a) and (1b).

\section{Experimental}


Cyanogen Iodide (ICN) was photolyzed by $266 \mathrm{~nm}$ light from the fourth harmonic of an Nd:YAG laser (Continuum Surelite-II):

$$
\mathrm{ICN}+h v(266 \mathrm{~nm}) \rightarrow \mathrm{CN}+\mathrm{I}
$$

$\mathrm{CN}$ radicals and $\mathrm{HCN}$ and DCN reaction products were detected by time-resolved infrared diode laser absorption spectroscopy using lead salt diode lasers (Laser Components) operating at 85 $110 \mathrm{~K}$. The infrared beam was collimated by a $\mathrm{CaF}_{2}$ lens and combined with the UV beam through use of a dichroic mirror. Both beams were restricted to $6 \mathrm{~mm}$ in diameter and passed through a $143 \mathrm{~cm}$ single pass absorption cell. The beams were separated by a monochromator, and the IR beam was focused onto a $1 \mathrm{~mm}$ InSb detection chip (Cincinnati Electronics, $\sim 1 \mu \mathrm{s}$ response time). Transient signals were recorded and signal averaged on a digital oscilloscope, then stored on a computer for analysis. Rate coefficient measurements were taken at 298, 322, 383 , and $421 \mathrm{~K}$. Isotope labeled rate coefficient measurements were performed at $298 \mathrm{~K}$. Product yield measurements were taken at 298K. Typical reaction conditions during rate coefficient measurements were $\mathrm{P}(\mathrm{ICN})=0.1$ Torr, $\mathrm{P}\left(\mathrm{SF}_{6}\right)=0.5$ Torr and variable pressures of the alcohol reagent. Typical reaction conditions in product yield measurements were $\mathrm{P}(\mathrm{ICN})=$ 0.1 Torr, $\mathrm{P}\left(\mathrm{CH}_{3} \mathrm{OH}\right)=1.0$ Torr, and $\mathrm{P}\left(\mathrm{SF}_{6}\right)=1.0$ Torr. $\mathrm{SF}_{6}$ was used as a buffer gas in order to quickly relax any nascent vibrationally excited product molecules to a Boltzmann distribution. Typical photolysis pulse energies were $\sim 7-8 \mathrm{~mJ} /$ pulse. Under these conditions, the temperature rise in the gas mixture due to UV laser absorption is negligible.

ICN (Fluka, 97\%) was purified by vacuum sublimation to remove any dissolved gasses. $\mathrm{CH}_{3} \mathrm{OH}$ (Sigma-Aldrich, 99.9\%), $\mathrm{CH}_{3} \mathrm{OD}$, and $\mathrm{CD}_{3} \mathrm{OH}$ (Cambridge Isotope Labs, 99\% and $99.5 \%$ isotopic purity, respectively) were purified by several freeze-pump-thaw cycles at $77 \mathrm{~K}$. $\mathrm{CH}_{3} \mathrm{CH}_{2} \mathrm{OH}$ (Sigma-Aldrich, 99.5\%) was purified by the same method. n-Propanol (Sigma-Alrdrich,99.80\%) was purified by several freeze-pump-thaw cycles at $77 \mathrm{~K} . \mathrm{SF}_{6}$ (Matheson) was purified by several freeze-pump-thaw cycles at 77K.

The following molecules were probed using IR diode laser absorption spectroscopy: 


$$
\begin{array}{ll}
\mathrm{CN}(v=1 \leftarrow v=0) & \mathrm{R}(4) \text { at } 2060.804 \mathrm{~cm}^{-1} \\
\mathrm{HCN}(v=1 \leftarrow v=0) & \mathrm{P}(17) \text { at } 3258.442 \mathrm{~cm}^{-1} \\
\text { and } \mathrm{P}(19) \text { at } 3251.823 \mathrm{~cm}^{-1} & \\
\mathrm{DCN}(v=1 \leftarrow v=0) & \mathrm{R}(17) \text { at } 2369.42 \mathrm{~cm}^{-1} \\
& \text { and } \mathrm{R}(7) \text { at } 2651.107 \mathrm{~cm}^{-1}
\end{array}
$$

The HITRAN database[25] was used for locating and identifying spectral lines of HCN. Other published sources were used to locate and identify spectral lines of CN[26] and DCN[27]. The transitions used are sufficiently close to the peak of the rotational Boltzmann distributions in order to minimize population changes from any small heating effects due to photolysis laser absorption.

\section{Results and Discussion}

\subsection{Total rate coefficients}

The total rate coefficient was measured by diode IR absorption spectroscopy detection of $\mathrm{CN}$ radicals. Figure 1 shows typical transient absorption signals obtained with and without added methanol reagent. These signals show a rapid rise in absorption attributed to photolytic formation of $\mathrm{CN}$ and rapid relaxation of the nascent hot rotational distribution to a thermal Boltzmann distribution of rotational levels. This occurs on a timescale of $<10 \mu \mathrm{s}$. Although vibrational relaxation may be much slower, the photolysis of ICN at $248 \mathrm{~nm}$ is known to produce primarily vibrational ground state $\mathrm{CN}$ radicals. In the absence of methanol, the observed decay rate of $\mathrm{CN}$ radicals was approximately $\sim 25 \mathrm{~ms}^{-1}$ over a $160 \mu$ s observation window. This non-zero decay is attributed to reactions other that the title reaction (primarily $\mathrm{CN}+\mathrm{CN}$ self reaction, reaction with trace $\mathrm{O}_{2}$ impurities, and diffusion of $\mathrm{CN}$ molecules out of the probed region). The decay rate increased to about $75 \mathrm{~ms}^{-1}$ upon addition of 0.1 Torr $\left(3.2 \times 10^{15}\right.$ molec $\left.\mathrm{cm}^{-3}\right)$ of $\mathrm{CH}_{3} \mathrm{OH}$. Typical CN radical densities at the photolysis pulse energies used were approximately $2.0 \times$ $10^{13}$ molecules $/ \mathrm{cm}^{3}$. Under these conditions, pseudo-first order conditions will be expected if 
the concentration of $\mathrm{CH}_{3} \mathrm{OH}$ is greater than $\sim 4 \times 10^{14}$ molecules $/ \mathrm{cm}^{3}=12 \mathrm{mTorr}$. Therefore, the time-dependent $\mathrm{CN}$ concentration may be described according to a standard pseudo-first order kinetics treatment:

$$
\begin{aligned}
& {[\mathrm{CN}]_{\mathrm{t}}=[\mathrm{CN}]_{0} \exp \left(-\mathrm{k}^{\prime} \mathrm{t}\right)} \\
& \mathrm{k}^{\prime}=\mathrm{k}_{1}\left[\mathrm{CH}_{3} \mathrm{OH}\right]+\mathrm{k}_{0}
\end{aligned}
$$

Where $\mathrm{k}^{\prime}$ is the observed pseudo-first order $\mathrm{CN}$ signal decay, $\mathrm{k}_{1}$ is the desired bimolecular rate coefficient, and $\mathrm{k}_{0}$ is the pseudo-first order decay in the absence of methanol reagent. Transient signals were fit to the above function to give $\mathrm{k}^{\prime}$ values, which were then plotted as a function of $\left[\mathrm{CH}_{3} \mathrm{OH}\right]$. A typical plot is shown in Figure 2. The slope of this plot is the desired bimolecular rate coefficient, $\mathrm{k}_{1}$. 


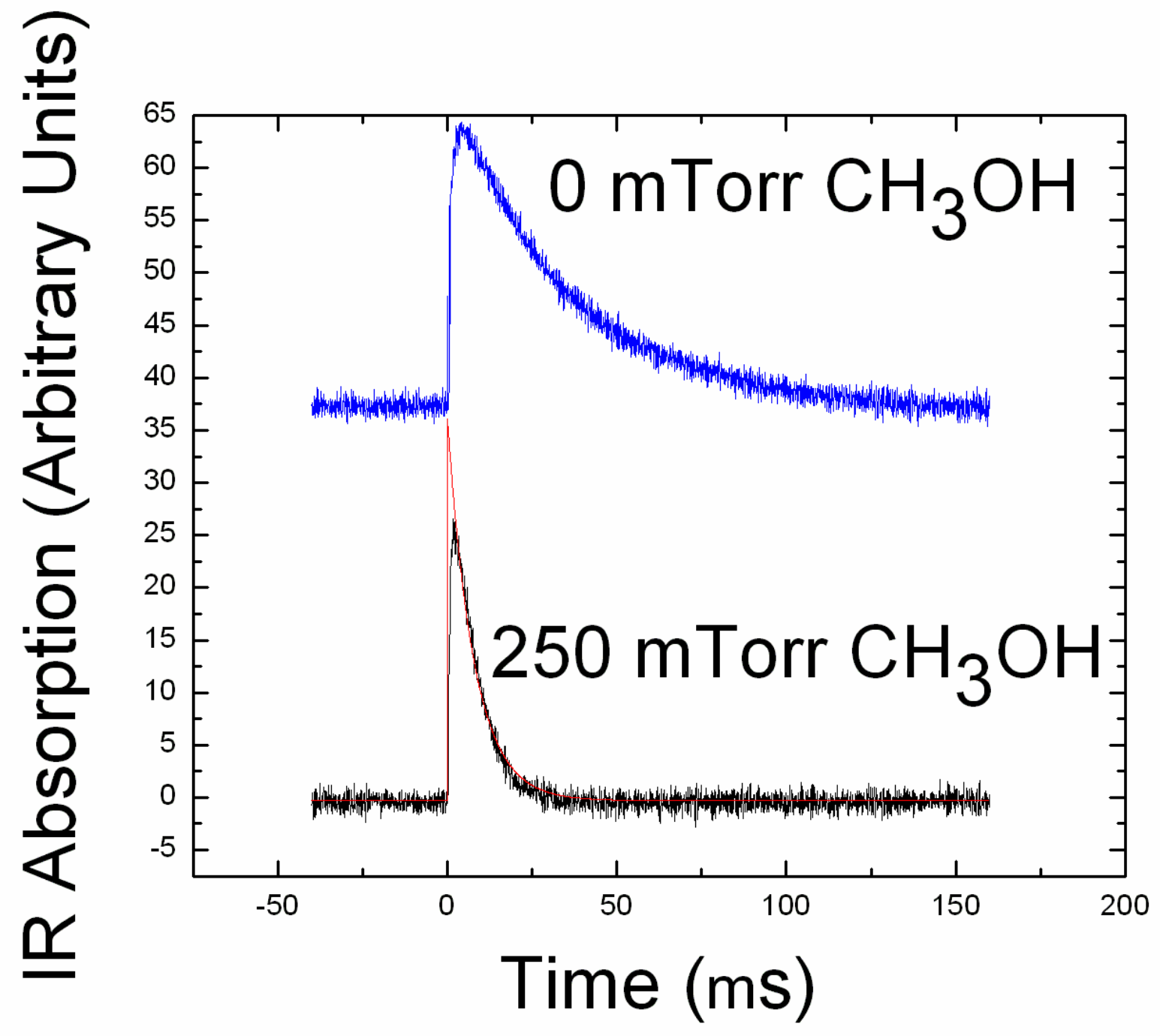

Figure 1: Infrared absorption transients, detecting [CN] vs time. Upper trace: without added alcohol reagent. Lower trace: with $250 \mathrm{mTorr}\left(8.1 \times 10^{15}\right.$ molec $\left.\mathrm{cm}^{-3}\right)$ of $\mathrm{CH}_{3} \mathrm{OH}$ reagent. Also shown on lower trace is a single exponential decay fit. Other conditions (both traces): $\mathrm{P}(\mathrm{ICN})=$ 0.10 Torr, $\mathrm{P}\left(\mathrm{SF}_{6}\right)=0.50$ Torr 


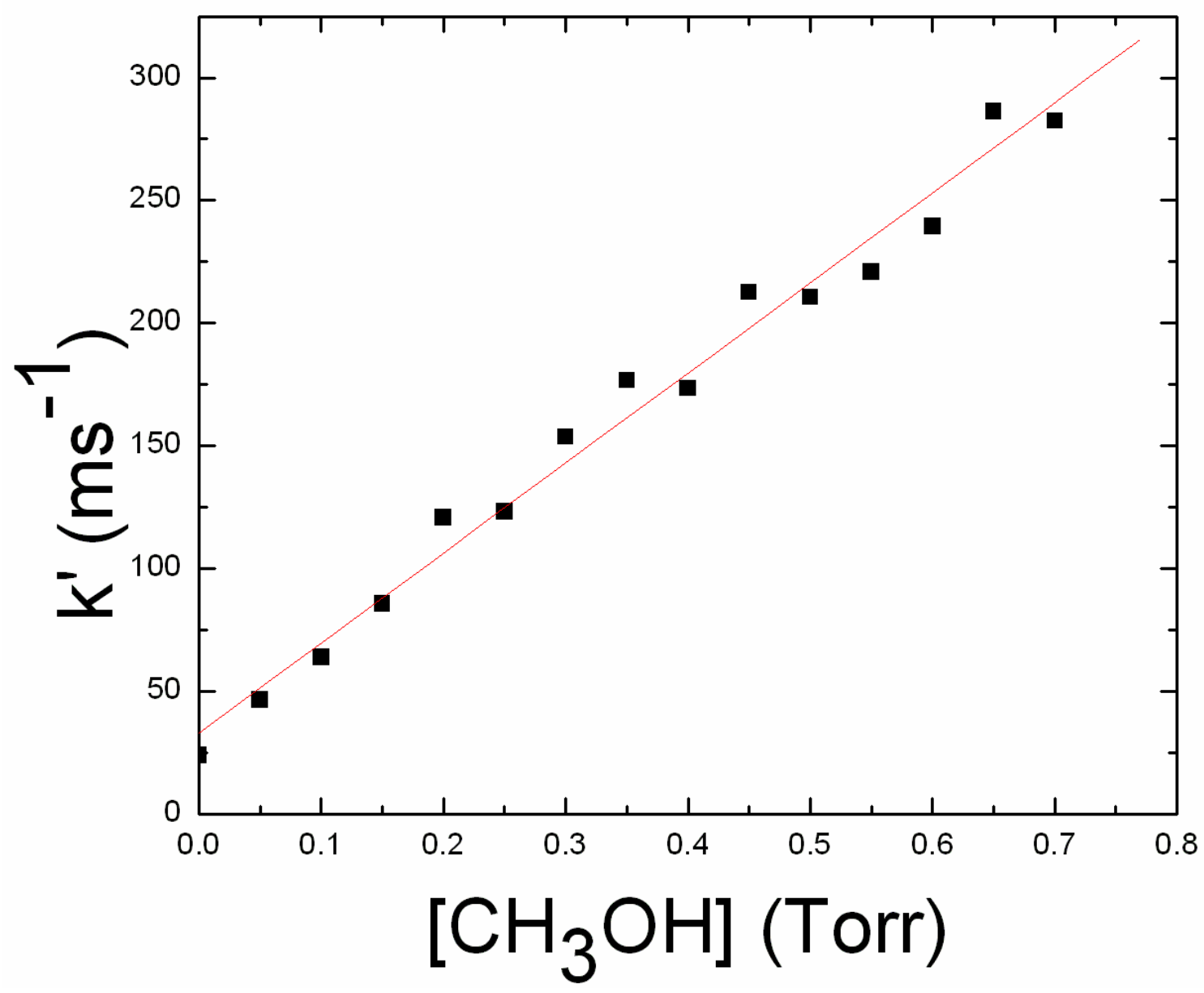

Figure 2: Plot of pseudo-first-order decay rate vs. pressure in Torr of $\mathrm{CH}_{3} \mathrm{OH}$. 
Rate coefficients of the $\mathrm{CN}+\mathrm{CH}_{3} \mathrm{OH}$ reaction were determined over the temperature range $(298-421 \mathrm{~K})$, as shown in Table 1. Figure 3 shows an Arrhenius plot of the data. Only a slight temperature dependence was observed, resulting in a large amount of relative scatter in this plot. From the slope and intercept, we obtain the expression:

$$
k_{1}(\mathrm{~T})=(2.16 \pm 0.46) \times 10^{-11} \exp [(-214 \pm 76) / \mathrm{T}] \mathrm{cm}^{3} \mathrm{molec}^{-1} \mathrm{~s}^{-1}
$$

From this equation the activation energy was determined to be $1.78 \pm 0.63 \mathrm{~kJ} \mathrm{~mol}^{-1}$. In addition, rate constant measurements at $298 \mathrm{~K}$ were performed for reactions of $\mathrm{CN}$ with ethanol and n-propanol. The results are shown in Table 2. 


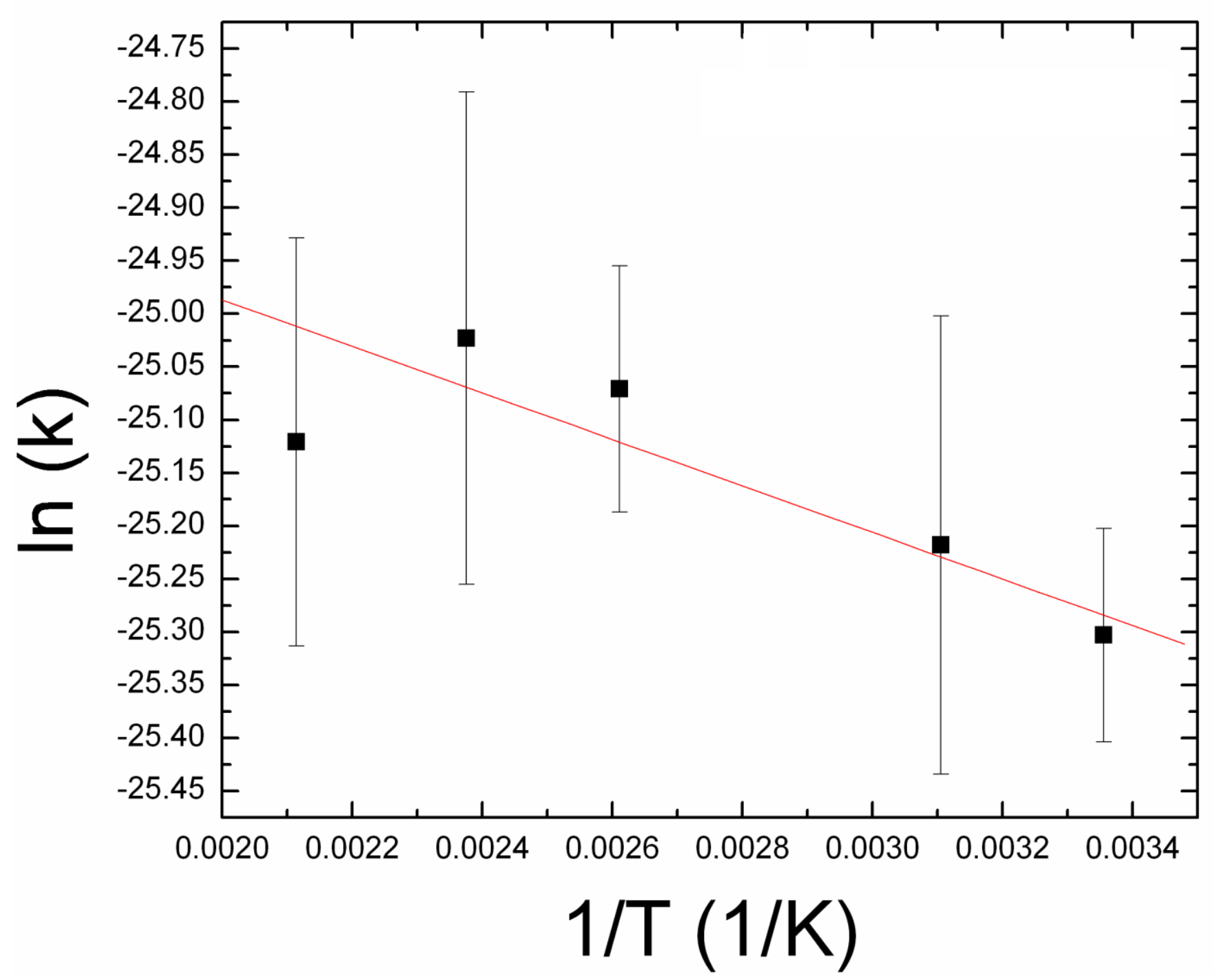

Figure 3: Arrhenius Plot of $\ln \mathrm{k}$ (with $\mathrm{k}$ in $\mathrm{cm}^{3} \mathrm{molec}^{-1} \mathrm{~s}^{-1}$ ) vs. 1/T, for the $\mathrm{CN}+\mathrm{CH}_{3} \mathrm{OH}$ reaction. Error bars represent one standard deviation. 
Table 1: Rate Coefficient of $\mathrm{CN}+\mathrm{CH}_{3} \mathrm{OH}$ vs. Temperaturea

\begin{tabular}{|c|c|}
\hline Temperature (K) & $\begin{array}{l}\text { Rate Coefficient } \\
\left(\mathrm{cm}^{3} \text { molecule }^{-1} \mathrm{~s}^{-1}\right)\end{array}$ \\
\hline 298 & $(1.03 \pm 0.10) \times 10^{-11}$ \\
\hline 322 & $(1.14 \pm 0.26) \times 10^{-11}$ \\
\hline 383 & $(1.30 \pm 0.16) \times 10^{-11}$ \\
\hline 421 & $(1.39 \pm 0.33) \times 10^{-11}$ \\
\hline 473 & $(1.25 \pm 0.25) \times 10^{-11}$ \\
\hline
\end{tabular}

aUncertainties represent one standard deviation.

Table 2: Rate Constants of CN + Alcohol Reactionsa

\begin{tabular}{|l|l|}
\hline Reaction & $\begin{array}{l}\text { Bimolecular Rate Coefficient }(298 \mathrm{~K}) \\
\left(\mathrm{cm}^{3} \text { molecule }^{-1} \mathrm{~s}^{-1}\right)\end{array}$ \\
\hline $\mathrm{CN}+\mathrm{CH}_{3} \mathrm{OH}$ & $(1.03 \pm 0.10) \times 10^{-11}$ \\
\hline $\mathrm{CN}+\mathrm{CH}_{3} \mathrm{OD}$ & $(1.19 \pm 0.09) \times 10^{-11}$ \\
\hline $\mathrm{CN}+\mathrm{CD}_{3} \mathrm{OH}$ & $(9.05 \pm 0.32) \times 10^{-12}$ \\
\hline $\mathrm{CN}+\mathrm{C}_{2} \mathrm{H}_{5} \mathrm{OH}$ & $(2.84 \pm 0.78) \times 10^{-11}$ \\
\hline $\mathrm{CN}+$ n-propanol & $(7.57 \pm 1.45) \times 10^{-11}$ \\
\hline
\end{tabular}

aUncertainties represent one standard deviation 


\subsection{Product Yields}

Infrared diode laser absorption spectroscopy was used to detect $\mathrm{HCN}$ and $\mathrm{DCN}$ products of the reactions of $\mathrm{CN}$ with $\mathrm{CH}_{3} \mathrm{OH}, \mathrm{CD}_{3} \mathrm{OH}$, and $\mathrm{CH}_{3} \mathrm{OD}$. In addition to reactions (1a) and (1b), above, the following reactions can occur when partially deuterated reagents are used:

$$
\begin{aligned}
\mathrm{CN}+\mathrm{CD}_{3} \mathrm{OH} & \rightarrow \mathrm{DCN}+\mathrm{CD}_{2} \mathrm{OH} \\
& \rightarrow \mathrm{HCN}+\mathrm{CD}_{3} \mathrm{O} \\
\mathrm{CN}+\mathrm{CH}_{3} \mathrm{OD} & \rightarrow \mathrm{HCN}+\mathrm{CH}_{2} \mathrm{OD} \\
& \rightarrow \mathrm{DCN}+\mathrm{CH}_{3} \mathrm{O}
\end{aligned}
$$

All detection experiments were performed at 298 K. Figure 4 shows a typical $\mathrm{HCN}$ product transient signal for the reactions of $\mathrm{CN}$ with $\mathrm{CH}_{3} \mathrm{OH}$ and $\mathrm{CD}_{3} \mathrm{OH}$. These signals exhibit a fast rise attributable to formation of $\mathrm{HCN}$ reaction products, followed by a slow decay that is due to diffusion of product molecules out of the probed volume. The peak-peak amplitudes of these signals were converted to absolute concentrations of HCN using known linestrengths from the HITRAN database, as described in previous publications[28]. Typical concentrations obtained under our experimental conditions were $\sim 1.92 \times 10^{13}$ molecule $\mathrm{cm}^{-3}$. In principle, if channels (1a) and (1b) are the only products of reaction (1), and if the $\mathrm{CH}_{3} \mathrm{OH}$ concentration is sufficient to ensure that all $\mathrm{CN}$ radicals react with $\mathrm{CH}_{3} \mathrm{OH}$, then the $\mathrm{HCN}$ yield should be equal to the initial $[\mathrm{CN}]_{0}$ produced in the photolysis. In practice, we find that with 1.00 Torr of $\mathrm{CH}_{3} \mathrm{OH}$, the $\mathrm{HCN}$ yield is typically only about $\sim 80 \%$ of $[\mathrm{CN}]_{0}$, suggesting that other pathways for $\mathrm{CN}$ removal exist; the intercepts apparent in Figure 2 are in qualitative agreement with this. In addition, however, the calculation of $[\mathrm{CN}]_{0}$ from the UV cross section of ICN and the photolysis laser pulse energy has a significant uncertainty of $\sim 15-20 \%$. Therefore, in order to normalize the $\mathrm{HCN}$ yields, the $\mathrm{HCN}$ yield in the following reaction was measured: 


$$
\mathrm{CN}+\mathrm{C}_{6} \mathrm{H}_{12} \text { (cyclohexane) } \rightarrow \mathrm{HCN}+\mathrm{C}_{6} \mathrm{H}_{11}
$$

Because this reaction is expected to form $\mathrm{HCN}$ in $100 \%$ yield, this provides a useful comparison. The resulting HCN number densities are shown in Table 3. The uncertainties in the number densities, which are larger than usual for these types of experiments, are primarily due to random errors caused by power drift in the photolysis and probe lasers. 


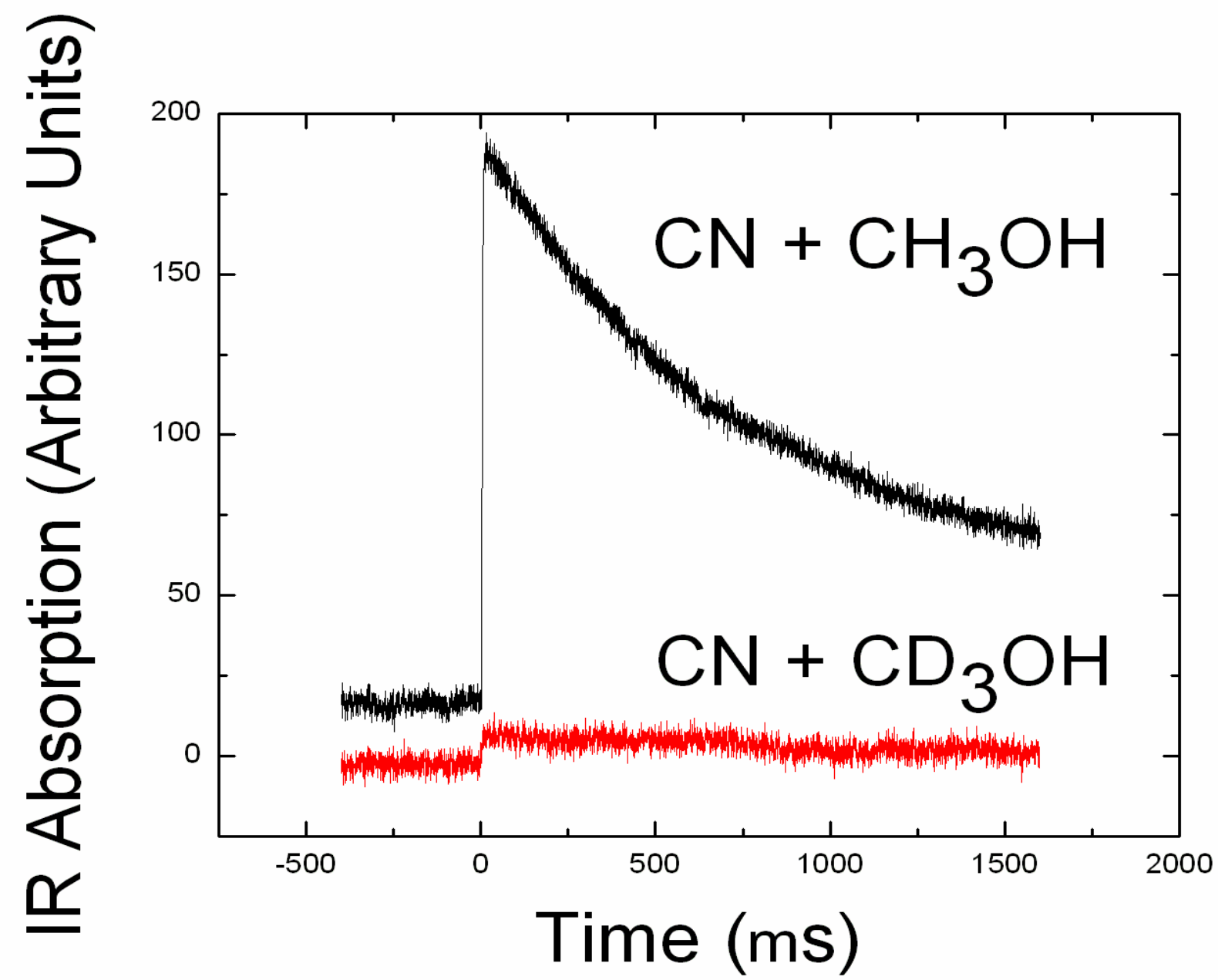

Figure 4: Transient infrared absorption signals for $\mathrm{HCN}$ product detection from the $\mathrm{CN}+\mathrm{CH}_{3} \mathrm{OH}$ and $\mathrm{CN}+\mathrm{CD}_{3} \mathrm{OH}$ reactions. $\mathrm{P}(\mathrm{ICN})=0.10$ Torr, $\mathrm{P}\left(\mathrm{CH}_{3} \mathrm{OH}\right)=1.00$ Torr (upper trace only), $\mathrm{P}\left(\mathrm{CD}_{3} \mathrm{OH}\right)=1.00$ Torr (lower trace only), $\mathrm{P}\left(\mathrm{SF}_{6}\right)=1.00$ Torr 
Table 3: HCN yields of $\mathrm{CN}$ reactions.

\begin{tabular}{|l|l|l|}
\hline Reaction & $\begin{array}{l}\text { Absolute Number Density } \\
\left(\text { molecule } \mathrm{cm}^{-3}\right)\end{array}$ & Normalized Number Density \\
\hline $\mathrm{CN}+\mathrm{C}_{6} \mathrm{H}_{12}$ & $(2.08 \pm 0.77) \times 10^{13}$ & $1.00 \pm 0.37$ \\
\hline $\mathrm{CN}+\mathrm{CH}_{3} \mathrm{OH}$ & $(1.92 \pm 0.86) \times 10^{13}$ & $0.92 \pm 0.41$ \\
\hline $\mathrm{CN}+\mathrm{CD}_{3} \mathrm{OH}$ & $(0.165 \pm 0.124) \times 10^{13}$ & $0.08 \pm 0.06$ \\
\hline $\mathrm{CN}+\mathrm{CH}_{3} \mathrm{OD}$ & $(1.55 \pm 0.52) \times 10^{13}$ & $0.74 \pm 0.25$ \\
\hline
\end{tabular}

Several conclusions may be obtained from the data. Firstly, the HCN yield of reaction (1) is approximately the same within experimental uncertainty as that of the reference reaction (6). This suggests that $\mathrm{HCN}$ forming channels, i.e. (1a) and (1b), do indeed dominate reaction (1), involving nondeuterated reagents. The $\mathrm{HCN}$ yield of reaction (4), however, is approximately an order of magnitude smaller. This indicates that channel (4b), abstraction of the hydroxyl hydrogen, is only a minor channel. The $\mathrm{HCN}$ yield of reaction (5) is close but slightly smaller than that of reaction (1), indicating that abstraction of the methyl hydrogen dominates. This result is not unexpected, as similar reactivity has been demonstrated in previous studies of $\mathrm{Cl}+\mathrm{CH}_{3} \mathrm{OH}$ kinetics[39]. We note that the isotopic purity of the deuterated samples is $\sim 99 \%$. A $1 \%$ impurity of $\mathrm{CH}_{3} \mathrm{OH}$ in the $\mathrm{CD}_{3} \mathrm{OH}$ sample would be insufficient to produce the observed $\mathrm{HCN}$ yields. We therefore conclude that while the expected alkyl abstraction channel dominates, a small but measurable yield of $\sim 8 \%$ into the hydroxyl channel (4b) is observed. We also note that it is unlikely that these results are affected by kinetic isotope effects, because such effects are very small (see Table 2), and even if they were significant, they would mainly affect the rise rate of the signals in Figure 4, not the resulting amplitudes.

DCN yields were also measured in a similar fashion, except that $\mathrm{C}_{2} \mathrm{D}_{6}$ rather than $\mathrm{C}_{6} \mathrm{H}_{12}$ was used as the reference reaction. Because we do not have linestrengths for DCN spectral transitions, we only measured relative yields, relative to the $\mathrm{CN}+\mathrm{C}_{2} \mathrm{D}_{6}$ reference reaction. The results are shown in Table 4. We find large amount of DCN formed in reaction (4), as expected if the alkyl abstraction channel (4a) dominates. We were able to detect only a very small DCN yield in reaction (5), suggesting that channel (5b) is very small. 
Table 4: DCN yields of $\mathrm{CN}$ reactions.

\begin{tabular}{|l|l|}
\hline Reaction & Normalized Number Density \\
\hline $\mathrm{CN}+\mathrm{C}_{2} \mathrm{D}_{6}$ & $1.00 \pm 0.38$ \\
\hline $\mathrm{CN}+\mathrm{CD}_{3} \mathrm{OH}$ & $0.93 \pm 0.14$ \\
\hline $\mathrm{CN}+\mathrm{CH}_{3} \mathrm{OD}$ & $0.02 \pm 0.01$ \\
\hline
\end{tabular}

\section{Conclusions}

Reactions of $\mathrm{CN}$ with $\mathrm{CH}_{3} \mathrm{OH}$ and partially deuterated analogues as well as higher primary alcohols were studied by infrared absorption spectroscopy. All of the probed reactions are fast, with rate constants increasing with alkyl chain length. Only very small isotope effects are observed in the total rate constants. HCN/DCN product detection experiments in the $\mathrm{CN}+$ methanol reaction demonstrate that abstraction from alkyl hydrogen or deuterium dominates, but a minor channel involving attack at the hydroxyl hydrogen is also observable. This reaction therefore represents a fairly clean route to producing the hydroxymethyl radical, $\mathrm{CH}_{2} \mathrm{OH}$.

\section{Acknowledgement}

This work was supported by Division of Chemical Sciences, Office of Basic Energy Sciences of the Department of Energy, Grant DE-FG03-96ER14645.

\section{References}

[1] D.L. Baulch, C.J. Cobos, R.A. Cox, P. Frank, G. Hayman, Th. Just, J.A. Kerr, T. Murrells, M.J. Pilling, J. Troe, R.W. Walker, and J. Warnatz, J. Phys. Chem. Ref. Data 23, (1994) 847, and references therein.

[2] C. Anastasi and D.U. Hancock, J. Chem. Soc., Faraday Trans. 2, 84, (1988) 9.

[3] D.A. Lichtin and M.C. Lin, Chem. Phys. 96, (1985) 473.

[4] R.J. Balla and K.H. Castleton, J. Phys. Chem. 95, (1991) 2344. 
[5] I.R. Sims, J.-L. Queffelec, D. Travers, B.R. Row, L.B. Herbert, J. Karthauser, I.W.M. Smith, Chem. Phys. Lett. 211, (1993) 461.

[6] L. Herbert I.W.M Smith, R.D. Spencer-Smith, Int. J. Chem. Kinet. 24 (1992) 791.

[7] D.L. Yang, T. Yu, M.C. Lin, C.F. Melius, Chem. Phys. 177 (1993) 271.

[8] H. Reisler, M. Mangir, and C. Wittig, Chem. Phys. 47, (1980) 49.

[9] M.Y. Louge and R.K. Hanson, Int. J. Chem. Kinet. 16, (1984) 231.

[10] I.R. Sims, J.-L. Queffelec, A. Defrance, C. Rebrion-Rowe, D. Travers, P. Bocherel, B.R. Rowe, and I.W.M. Smith, J. Chem. Phys. 100, (1994) 4229.

[11] R.C. Jensen, D.B. Walton, and R.D. Coombe, Ber. Bunsen-Ges. Phys. Chem. 169, (1990) 441.

[12] J.L. Durant, Jr. and F.P. Tully, Chem. Phys. Lett. 154, (1989) 568.

[13] B. Atakan, A. Jacobs, M. Wahl, R. Weller, and J. Wolfrum, Chem. Phys. Lett. 154, (1989) 449.

[14] M. Burmeister, S.K. Gulati, K. Natarajan, K. Theilen, E. Mozzhukin, and P. Roth, Symp. (Int.) Combust. (Proc.) 22, (1989) 1083.

[15] I.R. Sims and I.W.M. Smith, J. Chem. Soc. Faraday Trans. 89 (1993) 1.

[16] Y.Y. You and N.S. Wang, J. Chin. Chem. Soc. (Taipei) 40, (1993) 337.

[17] W. Tsang, J. Phys. Chem. Ref. Data 21 (1992) 753, and references therein.

[18] K.T. Rim and J.F. Hershberger, J. Phys. Chem. 103 (1999) 3721.

[19] W. Feng and J.F. Hershberger, J. Phys. Chem. 113 (2009) 3523.

[20] J. Park and J.F. Hershberger, J. Chem. Phys. 99 (1993) 3488.

[21] J. Park and J.F. Hershberger, Chem. Phys. Lett. 295, (1998) 89.

[22] W. Feng and J. F. Hershberger, J. Phys. Chem. A. 115, (2011) 286.

[23] W. Feng and J.F. Hershberger, J. Phys. Chem. A 110, (2006) 12184.

[24] W. Feng and J.F. Hershberger, J. Phys. Chem. A 116, (2012) 10285.

[25] L. S. Rothman, et al. J. Quant. Spectrosc. Radiat. Transfer. 48 (1992) 469.

[26] D. Cerny, R. Bacis, G. Guelachvili, F. J. Rousx. Mol. Spectrosc. 73 (1978) 154.

[27] E. Möllmann, M. Makib, A. G. Winnewissera, B. P. Winnewissera, W. Quapp. J. Mol. Spectrosc. 212 (2002) 22.

[28] S. Dóbé, T. Bérces, F. Temps, H. Gg. Wagner, H. Ziemer. Symp. Int. Comb. Proc. 25 (1994) 775. 